\title{
Effects of troxerutin on vascular inflammatory mediators and expression of microRNA-146a/NF-kB signaling pathway in aorta of healthy and diabetic rats
}

\author{
Che Xing*, Dai Xiang, and Li Caiying \\ Department of Vascular Surgery, Taizhou People's Hospital, Taizhou, Jiangsu province 225300, China
}

\section{ARTICLE INFO}

Received February 4, 2020

Revised April 19, 2020

Accepted May 1, 2020

*Correspondence

Che Xing

E-mail: tzchexing@sina.com

\section{Key Words}

Aorta

Diabetes mellitus

Nuclear factor-kappa B

Troxerutin

Vacscular injury

\begin{abstract}
This study has investigated the effect of a potent bioflavonoid, troxerutin, on diabetes-induced changes in pro-inflammatory mediators and expression of microRNA-146a and nuclear factor-kappa-B (NF-KB) signaling pathway in aortic tissue of type-I diabetic rats. Male Wistar rats were randomly divided into four groups $(n=6 /$ each): healthy, healthy-troxerutin, diabetic, and diabetic-troxerutin. Diabetes was induced by streptozotocin injection ( $60 \mathrm{mg} / \mathrm{kg}$; intraperitoneally) and lasted 10 weeks. Troxerutin ( $150 \mathrm{mg} / \mathrm{kg} /$ day) was administered orally for last month of experiment. Inflammatory cytokines IL-1 $\beta$, IL- 6 , and TNF- $\alpha$, as well as intercellular adhesion molecule-1 (ICAM-1), vascular cell adhesion molecule (VCAM), cyclooxygenase-II (COX-II), and inducible-nitric oxide synthase (iNOS) were measured on aortic samples by enzyme-linked immunosorbent assay. Gene expressions for transcription factor NF-KB, interleukin-1 receptor-associated kinase-1 (IRAK-1), TNF receptor-associated factor-6 (TRAF-6), and microRNA-146a were determined using real-time polymerase chain reaction. Ten-week diabetes significantly increased mRNA levels of IRAK-1, TRAF-6, NF-KB, and protein levels of cytokines IL-1 $\beta$, IL- 6 , TNF- $\alpha$, adhesion molecules ICAM-1, VCAM, and iNOS, COX-II, and decreased expression of microRNA-146a as compared with healthy rats $(p<0.05$ to $p<0.01)$. However, one month treatment of diabetic rats with troxerutin restored glucose and insulin levels, significantly decreased expression of inflammatory genes and pro-inflammatory mediators and increased microRNA level in comparison to diabetic group $(p<0.05$ to $p<0.01)$. In healthy rats, troxerutin had significant reducing effect only on NF-KB, TNF- $\alpha$ and COXII levels $(p<0.05)$. Beside slight improvement of hyperglycemia, troxerutin prevented the activation of NF-KB-dependent inflammatory signaling in the aorta of diabetic rats, and this response may be regulated by microRNA-146a.
\end{abstract}

\section{INTRODUCTION}

The increasing prevalence of vascular-related diseases such as atherosclerosis, cardiovascular events, retinopathy, and nephropathy during diabetes is a serious life-threatening concern all over the world. Indeed, vascular endothelial cells, vascular smooth muscle cells, and connective tissue cells are at risk of damage to hyperglycemia-induced oxidative stress and the subsequent sys- temic and local inflammation [1,2]. The available evidence has shown that endothelial dysfunction and adverse vascular remodeling accompanying diabetes are correlated with overexpression of inflammatory mediators along with increased nuclear factorkappa B (NF- $\mathrm{B}$ ) activity [3]. Results of convincing studies have demonstrated that the activated NF- $\mathrm{KB}$ signaling pathway in chronic diabetic conditions acts in a vicious cycle to upregulate the inflammatory genes and cytokines like interleukin-1 beta (c) (i) : This is an Open Access article distributed under the terms of the Creative Commons Attribution Non-Commercial License, which permits unrestricted non-commercial use, distribution, and reproduction in any medium, provided the original work is properly cited. Copyright @ Korean J Physiol Pharmacol, pISSN 1226-4512, elSSN 2093-3827
Author contributions: C.X., D.X., and L.C. contributed to the study conception and design, material preparation, data collection, and analysis. C.X. wrote the first draft of the manuscript and all authors commented on previous versions of the manuscript. All authors read and approved the final manuscript. 
(IL-1 $\beta$ ), IL-6, tumor necrosis factor-alpha (TNF- $\alpha$ ), and intercellular and vascular cell adhesion molecules (ICAM, VCAM), exacerbating the vascular tissue injury [4].

In addition, microRNAs (miRNAs), non-coding RNAs in the cell cytoplasm, have been known to be a regulator of gene expression through interaction with the complementary section of its target mRNAs, and play crucial physiological roles in cell function hemostasis as a suppressor or enhancer in gene expression. However, if the specific miRNAs gene in a particular tissue were dysregulated by inflammatory mediators, they would take part in many pathological situations like diabetes, influencing various cell signaling and inflammatory modulation [5]. In this sense, miRNA-146a is an important biomarker of inflammatory status which it would be considered as a new therapeutic target in the management of the related disease. So, the assessment of its dysregulation during diabetes can be a reliable approach to study the pathophysiological target pathways, especially the $\mathrm{NF}_{-\kappa} \mathrm{B}$ signaling pathway $[5,6]$. Results from previous studies have demonstrated that diabetes impaired the expression of miRNA-146a that led to the high-level activity of NF- $\mathrm{B}$-related inflammatory signaling and its adaptor proteins like interleukin-1 receptorassociated kinase-1 (IRAK-1) and TNF receptor-associated factor-6 (TRAF-6) in diabetic tissues [7,8]. Thus, the preventive and therapeutic strategies targeting these elements of inflammatory reactions during diabetes would be promising in minimizing the diabetes-induced vascular complications.

Troxerutin (trihydroxy-ethyl rutin) (Fig. 1), a natural bioflavonoid, has been reported to have many medicinal properties including anti-inflammatory, antioxidant, anti-apoptotic, antithrombotic and vasoprotective features, with fewer side effects $[9,10]$. In a study, troxerutin positively affects the hippocampus function by reducing oxidative stress and promoting learning and memory in streptozotocin-induced type I diabetic rats [11]. Also, previous studies revealed anti-apoptotic and anti-inflammatory effects of troxerutin against myocardial ischemia/reperfusion in-

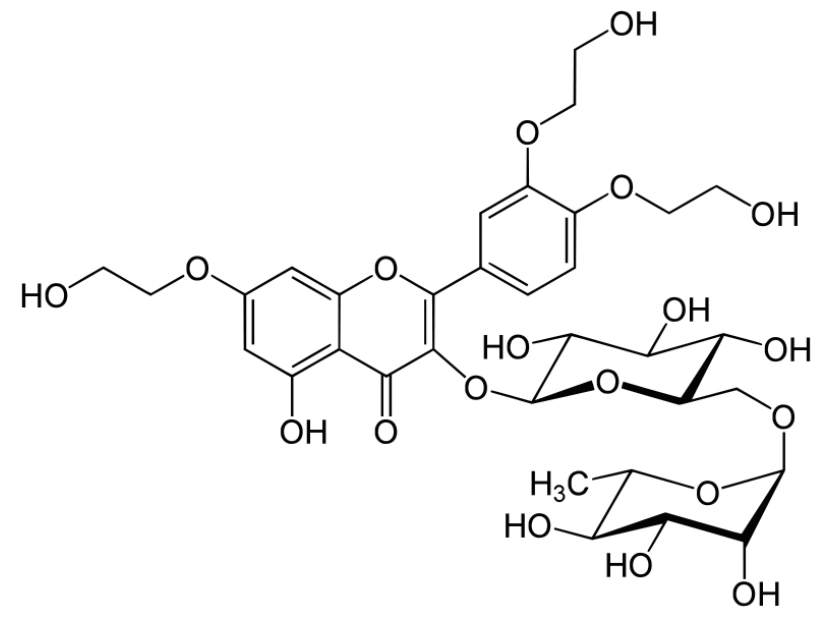

Fig. 1. Chemical structure of troxerutin. jury through the prevention of the cell-cell interaction in healthy rats [12], and anti-oxidative effect on aortic tissue of diabetic rat trough enhancing tissue antioxidant system activity and declining lipid peroxidation level [13]. Besides, in another study in healthy rats, troxerutin has exerted a myocardial protective effect against ischemia/reperfusion injury as preconditioning via the anti-apoptosis process by regulating miR-146a downregulation [12].

Thus, due to the encouraging potentials of troxerutin in alleviating the oxidative-inflammatory conditions in cardiovascular medicine, and the significant roles of vascular inflammatory responses and related miRNA in diabetes pathophysiology, in this study, we investigated the preventive effects of troxerutin on the miRNA-146a/NF- $\kappa$ B signaling pathway, and endothelial and vascular cell inflammatory mediators in aortic tissue of healthy and diabetic rats.

\section{METHODS}

\section{Animals and materials}

The study was carried out with thirty-two male Wistar rats (7-8 months) weighing 200-230 grams. Animals were kept in polypropylene cages and experienced a 12 -h light/12-h dark, 50\% humidity and temperature of $25^{\circ} \mathrm{C}$ and had free access to food and water. This study was approved by the local committee for animal care under ethical number IACUC-2019(1)1025, and the Guidelines for the Care and Use of Laboratory Animals published by the US National Institutes of Health (NIH publication No 8523 , revised 1996) were followed throughout the study. Troxerutin was purchased from Sigma (St. Louis, MO, USA) and all other chemicals and reagents were obtained from commercial sources in the highest quality available.

\section{Experimental design and induction of diabetes}

Animals were randomly divided into four groups ( $n=6$ in each group) including healthy control (Healthy-Cont), healthy with troxerutin (Healthy-TXR), diabetic control (Diabetic-Cont), and diabetic with troxerutin (Diabetic-TXR). Type-I Diabetes was induced by a single intraperitoneal injection of streptozotocin (STZ; $60 \mathrm{mg} / \mathrm{kg}$; dissolved in 0.1 molar citrate buffer with $\mathrm{pH}$ 4.5). The healthy rats received the same amount of citrate buffer alone. The development of diabetes was confirmed by measuring the blood glucose levels, $72 \mathrm{~h}$ after injection. The animals with blood glucose levels higher than $300 \mathrm{mg} / \mathrm{dl}$ were considered diabetic and those with blood glucose levels lower than this value were excluded from the experiment [14]. After six weeks of STZ injection, troxerutin $(150 \mathrm{mg} / \mathrm{kg} /$ day $)$ was administered orally for four weeks [15]. The experimental period lasted ten weeks in all groups. 


\section{Sampling and tissue processing}

At the end of the experimental duration, the blood glucose in fasted-rats from each group was measured using a glucometer. Then, the animals were weighed and anesthetized with an intraperitoneal injection of $60 \mathrm{mg}$ ketamine and $10 \mathrm{mg}$ xylazine per $\mathrm{kg}$ of body weight. The thoracic aorta was immediately removed and rinsed in cold saline and weighed. The aortic tissue was frozen by liquid nitrogen and stored in a $-80^{\circ} \mathrm{C}$ refrigerator. Then the aortic samples were homogenized in lysis buffer at $\mathrm{pH} 7.4$ in the presence of protease inhibitor cocktail (Sigma-Aldrich). Then, the homogenate was centrifuged at $10,000 \mathrm{rpm}$ for $10 \mathrm{~min}$ at $4^{\circ} \mathrm{C}$. The supernatants were removed from the homogenates and quickly frozen at $-80^{\circ} \mathrm{C}$. The protein concentration of the supernatant was estimated using the Bradford technique.

\section{Measurement of inflammatory cytokines, enzymes and adhesion molecules}

In all aortic tissue, the total RNA was extracted using Alterations of the pro-inflammatory cytokines and mediators in aortic samples of the experimental groups were evaluated using the enzyme-linked immunosorbent assay (ELISA) methods. Rat specific ELISA kits were used to detect the tissue levels of proinflammatory cytokines IL-6, IL-1 $\beta$ and TNF- $\alpha$, and activity of enzymes including inducible nitric oxide synthase (iNOS) and cyclooxygenase-II (COX-II), and adhesion molecules ICAM-1 and VCAM (MyBiosource, Inc., San Diego, CA, USA), according to the kits guidelines provided by the manufacturers. Fifty microliters of each supernatant and standard were mixed with assay buffers in duplicates according to the instructions. The absorbance was measured at $450 \mathrm{~nm}$ using a microplate ELISA reader (Lab System, Helsinki, Finland). The optical densities were normalized according to the corresponding standard curves and the resultant values expressed as $\mathrm{pg} / \mathrm{mg}$ of protein in each sample.

\section{Real-time PCR assessments of mRNAs and miRNA}

In all aortic tissue, the total RNA was extracted using the miRCURY RNA Isolation Kit (Exiqon, Vedbaek, Denmark) according to the manufacturer's instructions. To measurement of the quantity and quality of the isolated RNA were made in a Nano- drop spectrophotometer (Thermofisher Scientific, Waltham, MA, USA). The content of each sample was at least $200 \mathrm{ng} / \mu \mathrm{l}$. The cDNA synthesis from RNA was performed with the specific cDNA Synthesis kit (Fermentas GmBH, St. Leon-Rot, Germany) with the aid of random hexamer primers and MMLV reverse transcriptase and then the mRNA expressions were obtained using specific primers for each inflammatory mRNAs and miRNA, including NF- $\mathrm{B}$, IRAK-1 and TRAF-6, miRNA-146a, and housekeeping genes GAPDH and U6. Each cDNA was used as a template for real time PCR analysis employing the SYBR Green master mix (Exiqon, Vedbaek, Denmark), based on the instruction. The forward and reverse primer sets, respectively, for NF- $\kappa \mathrm{B}$ were AATTGCCCCGGCAT and TCCCGTAACCGCGTA, for IRAK-1 were GCTGTGGACACCGAT and GCTACACCCATCCACA, for TRAF-6 were CAGTCCCCTGCACATT and GAGGAGGCATCGCAT, for GAPDH were CCCATCACCATCTTCCAGGAG and GAAGGGGCGGAGATGATGAC, and for miRNA-146a was UGAGAACUGAAUUCCAUGGGUU. The PCR reactions were conducted on a Bio-Rad iQ5 Detection System (Bio-Rad, Richmond, CA, USA). The $2^{-\Delta \Delta \mathrm{Ct}}$ algorithm was used to determine and analyze the expression levels of each mRNA and miRNA.

\section{Statistical analysis}

Data are expressed as means \pm standard error. Differences of parameters between the groups were analyzed using one-way ANOVA followed by Tukey's test, as appropriate. p-value of less than 0.05 was considered statistically significant.

\section{RESULTS}

\section{Body weights, and plasma levels of glucose and insulin}

There was no significant difference in initial body weights among experimental groups (Table 1). After ten weeks of the diabetic period, the final body weight and plasma insulin concentration decreased $(p<0.05)$ and plasma glucose level increased $(\mathrm{p}<0.01)$ in diabetic control rats in comparison with the healthy control group. Troxerutin in treated-diabetic rats inhibited the

Table 1. The effect of troxerutin on body weight and blood glucose and insulin levels in healthy and diabetic rats

\begin{tabular}{ccccc}
\hline Groups & Initial body weight $(\mathrm{g})$ & Final body weight $(\mathrm{g})$ & Blood glucose $(\mathrm{mg} / \mathrm{dl})$ & Insulin level $(\mathrm{ng} / \mathrm{ml})$ \\
\hline Healthy-Cont & $206 \pm 9$ & $221 \pm 16$ & $97 \pm 15$ & $3.80 \pm 1.01$ \\
Healthy-TXR & $211 \pm 7$ & $246 \pm 19$ & $93 \pm 10$ & $4.26 \pm 1.06$ \\
Diabteic-Cont & $214 \pm 11$ & $183 \pm 13^{\mathrm{a}}$ & $426 \pm 38^{\mathrm{b}}$ & $1.40 \pm 0.30^{\mathrm{b}}$ \\
Diabetic-TXR & $209 \pm 8$ & $214 \pm 17$ & $302 \pm 27^{\mathrm{c}}$ & $2.36 \pm 0.90^{\mathrm{c}}$ \\
\hline
\end{tabular}

Values are presented as mean \pm standard error. $\mathrm{n}=6$ for each groups. Cont, control; TXR, troxerutin. ${ }^{\mathrm{a}} \mathrm{p}<0.05$ and ${ }^{\mathrm{b}} \mathrm{p}<0.01 \mathrm{vs}$. Healthy-Cont group; and ${ }^{c} p<0.05$ vs. Diabetic-Cont group. 
diabetes-induced loss of final body weight and considerably reduced the glucose level and significantly increased the plasma insulin level $(p<0.05)$, as compared with those of diabetic control rats (Table 1).

\section{Expression of NF- $\mathrm{kB}$, IRAK-1, and TRAF- 6 genes in aortic tissue}

Gene expression assessment using real-time PCR showed that the mRNA levels of NF- $\kappa$ B, IRAK-1, and TRAF- 6 genes in aortic samples of rats were significantly increased in the diabetic group in comparison with the healthy control group ( $\mathrm{p}<0.05$ for NF$\kappa \mathrm{B} \&$ IRAK-1; and $\mathrm{p}<0.01$ for TRAF-6) (Fig. 2). However, preadministration of troxerutin in diabetic rats significantly reduced the expression of all these genes as compared with the diabetic control group $(p<0.05)$. In healthy non-diabetic rats, troxerutin significantly decreased only NF- $\kappa \mathrm{B}$ expression in comparison to the healthy control rats, but it had no significant effect on IRAK1, and TRAF-6 genes (Fig. 2). These results demonstrated the suppressing effect of troxerutin on the vascular expression of NF$\kappa \mathrm{B}$ and its adaptor molecules in type-I diabetic rats.

\section{Expression of miRNA-146a in aortic tissue}

Induction of diabetes significantly reduced the expression of miRNA-146a as compared with the healthy group ( $\mathrm{p}<0.05$; Fig. 3). The pretreatment of healthy rats with troxerutin for one month could not influence the expression of miRNA-146a when compared to healthy controls. However, in diabetic rats, troxeru-
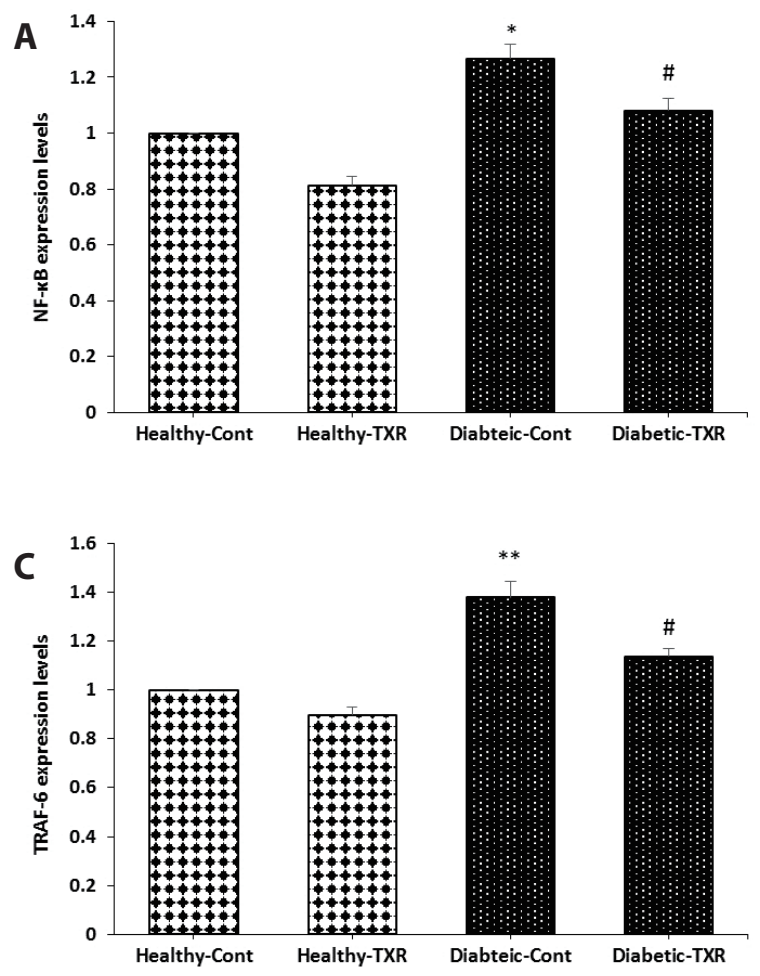

Korean J Physiol Pharmacol 2020;24(5):395-402 tin significantly raised the expression of this anti-inflammatory miRNA as compared with the diabetic control group $(\mathrm{p}<0.01)$.

\section{Levels of pro-inflammatory cytokines in aortic tissue}

The aortic levels of IL- 6 , IL-1 $\beta$, and TNF- $\alpha$ were measured as the main indicators of vascular pro-inflammatory cytokines activity. As shown in Fig. 4, the levels of these cytokines were significantly increased following the induction of diabetes in comparison to the healthy control group ( $p<0.05$ for IL- 6 and $p<0.01$ for others). Although administration of troxerutin had significant effects on only TNF- $\alpha(\mathrm{p}<0.05)$ in healthy non-diabetic rats, this bioflavonoid significantly reduced the levels of IL- 6 , and IL-1 $\beta$ $(\mathrm{p}<0.05)$, and TNF- $\alpha(\mathrm{p}<0.01)$ in treated diabetic group versus diabetic controls (Fig. 4, respectively).

\section{Levels of adhesion molecules in aortic tissue}

ICAM-1, and VCAM are two adhesion molecules which are involved in the interactions between inflammatory and endothelial/vascular cells. Again, induction of diabetes caused the significant elevation of molecules ICAM-1 $(\mathrm{p}<0.01)$ and VCAM$1(\mathrm{p}<0.05)$ in comparison to those of healthy control group (Fig. 5 , respectively). Pre-administration of troxerutin to the diabetic rats significantly reduced the diabetes-induced elevation of ICAM-1 levels toward healthy control values $(\mathrm{p}<0.05)$.

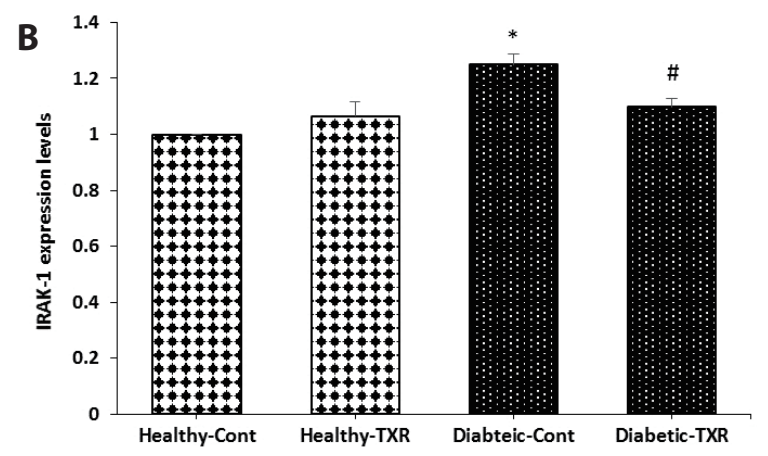

Fig. 2. Real-time $P C R$ analysis of genes expressions in the aortic tissue. The expression (mRNA) levels of NF-KB (A), IRAK-1 (B) and TRAF6 (C). The data were expressed as mean \pm standard error. $n=6$ for each group. NF- $\kappa B$, nuclear factor kappa B; IRAK-1, interleukin-1 receptorassociated kinase-1; TRAF-6, tumor necrosis factor receptor-associated factor-6; Cont, control; TXR, troxerutin. ${ }^{*} p<0.05$, and ${ }^{* *} p<0.01$ vs. Healthy-Cont group; and ${ }^{\#} p<0.05$ vs. Diabetic-Cont group. 


\section{Levels of iNOS and COX-II in aortic tissue}

Besides pro-inflammatory cytokines, two related enzymatic mediators iNOS and COX-II are intracellular targets for the $\mathrm{NF}-\kappa \mathrm{B}$ transcription factor during inflammatory conditions. In healthy control rats, troxerutin pretreatment significantly reduced the COX-II level $(\mathrm{p}<0.05)$ but not the iNOS level. The levels of these two mediators were significantly elevated by the induction of diabetes as compared with healthy control rats $(\mathrm{p}<0.01$; Fig. 6). Conversely, pre-treatment of diabetic rats with troxerutin for 4 weeks significantly inhibited the diabetes-induced elevation of both iNOS and COX-II levels as compared with those of the diabetic control group $(p<0.05)$. Overall, these results confirmed

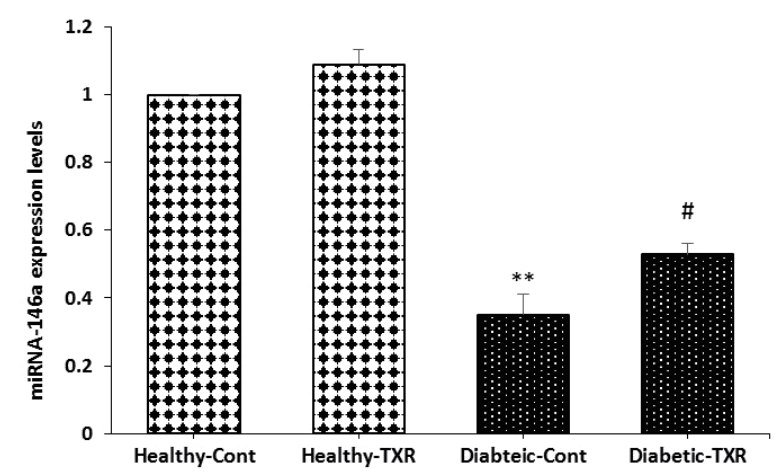

Fig. 3. Real-time PCR analysis of miR-146a expression in the aortic tissue. The data were expressed as mean \pm standard error. $n=6$ for each group. Cont, control; TXR, troxerutin. ${ }^{* *} \mathrm{p}<0.01$ vs. Healthy-Cont group; and $\# p<0.05$ vs. Diabetic-Cont group.
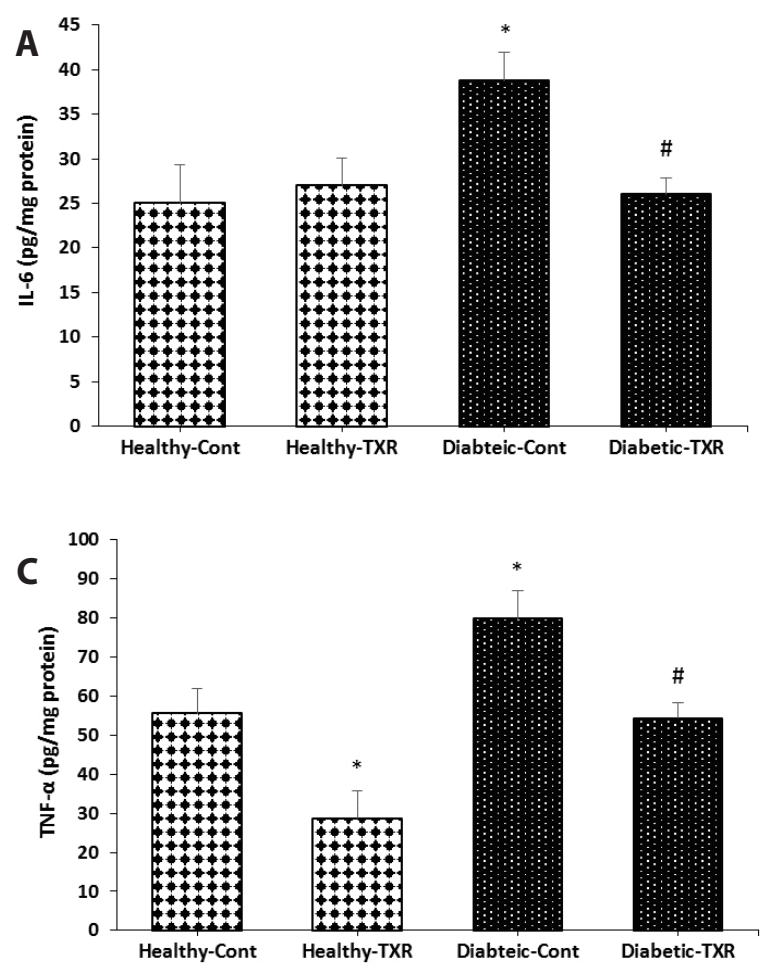

that the anti-inflammatory and endothelial-improving effects of troxerutin on the aortic tissue of diabetic rats are likely achieved by the regulation of the elements of the NF- $\mathrm{B}$ signaling pathway.

\section{DISCUSSION}

Findings from this study demonstrated that pretreatment of STZ-induced diabetic rats corrected the hyperglycemia and hypoinsulinemia to some extent and led to a decrease in the expression of IRAK-1, TRAF- $6, \mathrm{NF}-\kappa \mathrm{B}$ genes that followed by a decrease in pro-inflammatory cytokines (IL-1 $\beta$, IL-6, TNF- $\alpha$ ), inflammatory-related enzymes (iNOS, COX-II), and adhesion molecules (ICAM-1, VCAM), as well as an increase in the expression of miRNA-146a gene in the aortic tissue. Troxerutin administration counteracted these type-I diabetes-induced alterations, indicating its broad and significant anti-inflammatory effects in aortic tissue.

The available data suggest that diabetic-related vascular dysfunctions, especially endothelial impairments, manifest as atherosclerosis, cardiovascular complications, retinopathy, nephropathy and so on [16]. The relevant mechanisms of endothelial dysfunction during diabetes include impaired NO synthase function and reduced NO bioavailability through lack of PI3 kinase/Akt pathway [17,18], increased oxidative stress and inflammatory processes $[3,4,16]$, over-activation of $\operatorname{PKC} \beta[19]$, and mitochondrial dysfunction [20]. Activated endothelial cells produce inflammatory cytokines such as IL-6, monocyte chemotactic protein-1 and adhesion molecules including ICAM-1, VCAM in

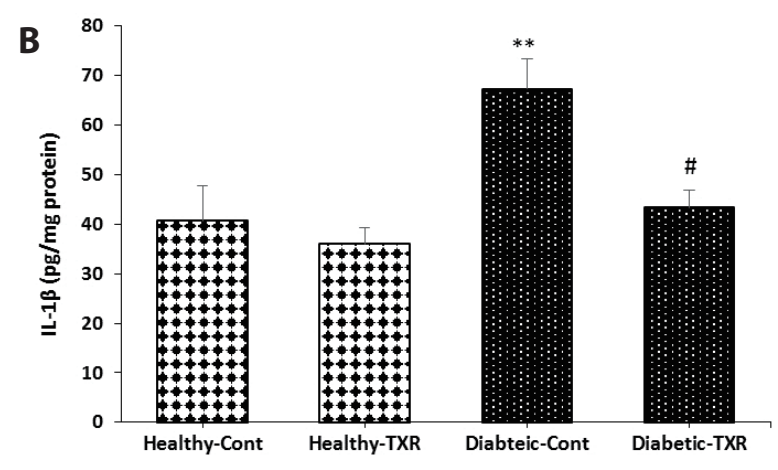

Fig. 4. The levels of inflammatory cytokines in the endothelial cells of aortic tissue. IL- 6 (A), IL-1 $\beta$ (B) and TNF- $\alpha$ (C). The data were expressed as mean \pm standard error. $\mathrm{n}=6$ for each group. IL, interleukin; TNF- $\alpha$, tumor necrosis factor- $\alpha$; Cont, control; TXR, troxerutin. ${ }^{*} p<$ 0.05 and ${ }^{* *} \mathrm{p}<0.01$ vs. Healthy-Cont group; and ${ }^{\#} \mathrm{p}<0.05$ vs. DiabeticCont group. 

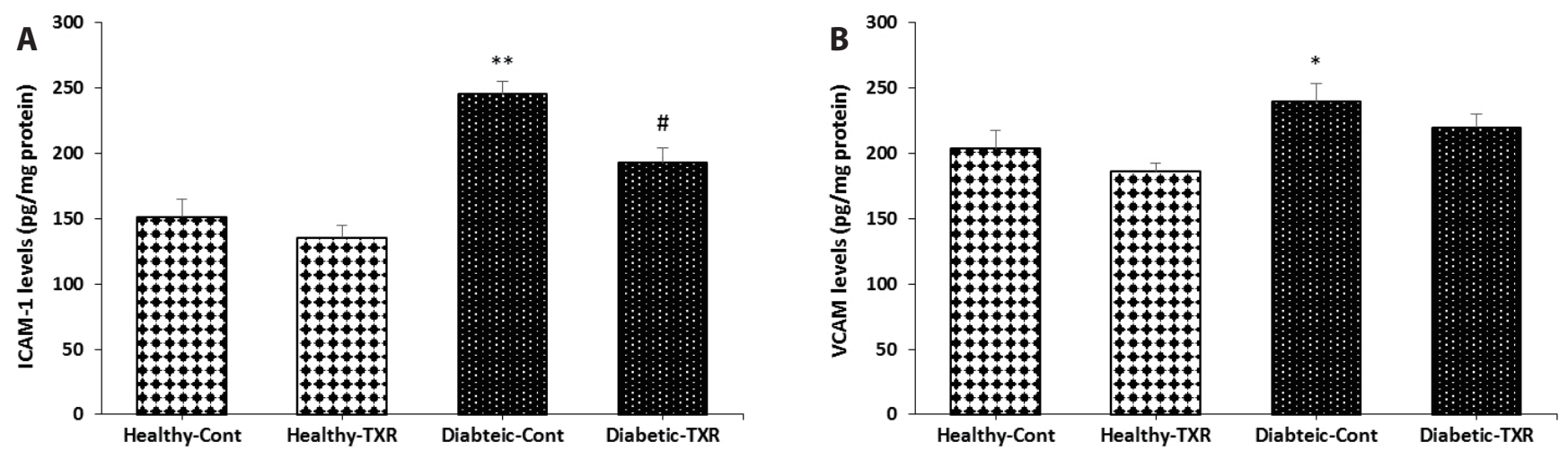

Fig. 5. The levels of adhesion molecules in aortic tissue. ICAM-1 (A), VCAM (B). The data were expressed as mean \pm standard error. $n=6$ for each group. ICAM-1, intercellular adhesion molecule-1; VCAM, vascular cell adhesion molecule; Cont, control; TXR, troxerutin. ${ }^{*} p<0.05$ and ${ }^{* *} p<0.01$ vs. Healthy-Cont group; and ${ }^{\#} \mathrm{p}<0.05$ vs. Diabetic-Cont group.
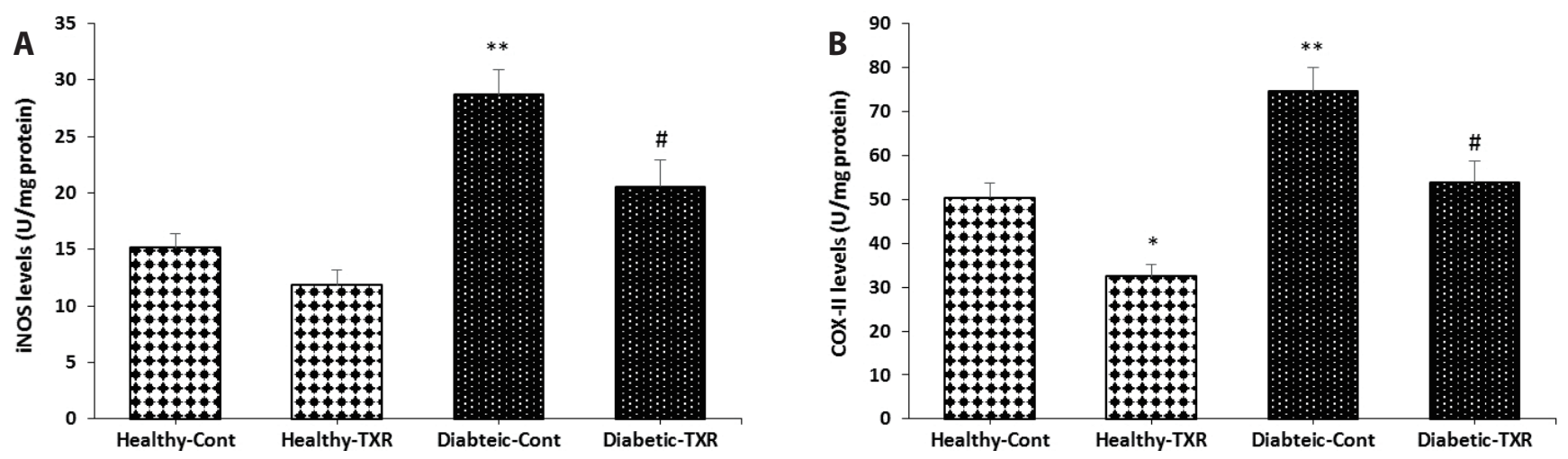

Fig. 6. The levels of inflammatory inducible enzymes in aortic tissue. iNOS (A), and COX-II (B). The data were expressed as mean \pm standard error. $n$ $=6$ for each group. iNOS, inducible-nitric oxide synthase; COX-II, cyclooxygenase-Il; Cont, control; TXR, troxerutin. ${ }^{*} p<0.05$ and ${ }^{* *} p<0.01$ vs. HealthyCont group; and $\#$ p $<0.05$ vs. Diabetic-Cont group.

arterial tissue [21,22]. It has known that in type-I diabetes, oxidative stress-induced inflammation associates with overexpression of Toll-like receptors on the lymphoid cells of the immune system, which are stimulated by receptor ligands, damage-associated molecular patterns, and inflammatory cytokines, especially TNF- $\alpha$ in damaged cells. The activation of Toll-like receptors activate the NF- $\kappa \mathrm{B}$ signaling (IRAK-1/TRAF-6/NF- $\mathrm{B}$ pathway), leading to gene upregulation of pro-inflammatory cytokines (IL$1 \beta$, IL-6, and TNF- $\alpha$ ), intercellular and vascular cell adhesion molecules, inducible enzymes (iNOS and COX-II) that induce more pro-inflammatory state in different cell type and diseases, such as type-I diabetes and atherosclerosis [23,24]. In line with previous studies, STZ-induced diabetes in this experiment caused more inflammatory responses that were established with increasing IL-1 $\beta$, IL- 6 , and TNF- $\alpha$, ICAM-1, VCAM, iNOS, and COX-II accompanying NF- $\kappa \mathrm{B}$ pathway activation in the aortic tissue. The administration of troxerutin significantly reversed the diabetesinduced changes. Results of previous studies have confirmed that troxerutin has anti-oxidative and anti-inflammatory functions in different vascular and non-vascular tissue types [9-11]. Although, in the present study, treatment of type-I diabetic rats with troxerutin slightly influenced hyperglycemia, the effects of this bioflavonoid on diabetic-provoked inflammatory conditions were substantial. As previous studies have reported that the antiinflammatory effect of troxerutin might be accomplished by suppressing NF- $\kappa \mathrm{B}$ activation in non-vascular tissues [25], our results revealed the involvement of this mechanism in vascular tissue, so that troxerutin repressed IRAK-1/TRAF-6/NF- $\mathrm{B}$ p pathway in aortic and improved the activity of vascular inflammatory mediators.

Recently, the miRNAs-NF- $\kappa B$ pathway has been considered as a new target for manipulating and preventing the concomitant diabetic-induced conditions [26]. The decreased miRNA-146 expression has been reported in peripheral blood mononuclear cells of patients with type-I diabetes [27,28], and endothelial cells of mice [29]. Similarly, in this study, the improving effects of troxerutin on inflammatory reactions and intercellular adhesion molecules were associated with enhanced expression of miRNA146a in aortic tissue of type-I diabetic rats. MiRNA-146a has been reported as a potent anti-inflammatory regulator in various diseases associated with inflammation and oxidative stress. Sustained inflammation and oxidative stress in various cell types 


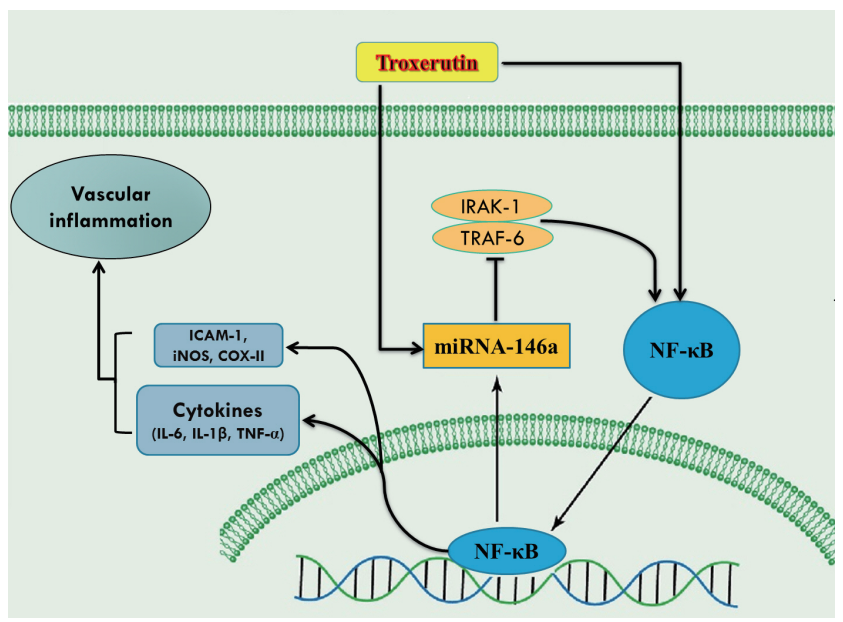

Fig. 7. Conceptual diagram of the study. NF- $\kappa B$, nuclear factor kappa B; IRAK-1, interleukin-1 receptor-associated kinase-1; TRAF-6, tumor necrosis factor receptor-associated factor-6; ICAM-1, intercellular adhesion molecule- 1 ; IL, interleukin; TNF- $\alpha$, tumor necrosis factor- $\alpha$.

stimulate the expression of miRNA-146a through activated transcription factor NF- $\mathrm{B}$. Increased miRNA-146a expression, in turn, could block the expression of its target genes such as IRAK1 and TRAF6, downregulating the activation of Toll-like receptor/ NF-кB-mediated inflammation and over-activation of cytokines, iNOS, COX-II and ICAM-1. During the inflammation, the TRAF6/NF- $\kappa$ B pathway is strongly regulated by a negative feedback regulatory loop with miRNA-146a as a key component, serving to protect tissues against inflammatory reactions. Here, the NF- $\kappa$ B may have self-regulating activity [29-32]. Therefore, troxerutin modulates the miRNA-146a/NF- $\kappa$ B inflammatory signaling pathway to play as a regulatory negative feedback loop and reduce the inflammatory outcomes of diabetes in aortic tissue (Fig. 7). It seems that further studies with direct manipulation of miRNA-146a expression and its methylation are required to find an association between this miRNA and beneficial effects of troxerutin on endothelial cells and inflammatory responses as well as oxidative stress in diabetic animals. Since the oxidative stress and inflammatory reactions have crucial reciprocal effects to boost each other, it is better to investigate the anti-inflammatory and anti-oxidative effects of troxerutin in parallel in diabetic vessels and the cross-talk of these mechanisms through interaction with miRNA-146a.

In conclusion, troxerutin therapy alleviated the diabeticinduced overproduction of inflammatory cytokines, as well as the endothelial adhesion molecule and inducible enzymes via regulating miRNAs-NF- $\mathrm{KB}$ signaling pathway in the aorta of STZ-induced diabetic rat (Fig. 7). The present results imply the protective effects of troxerutin on vascular complications of typeI diabetes.

\section{ACKNOWLEDGEMENTS}

The authors would like to thank Taizhou People's Hospital, Jiangsu, China, for their supports to this study.

\section{CONFLICTS OF INTEREST}

The authors declare no conflicts of interest.

\section{REFERENCES}

1. Rask-Madsen C, King GL. Vascular complications of diabetes: mechanisms of injury and protective factors. Cell Metab. 2013;17:2033.

2. Nicholls SJ, Tuzcu EM, Kalidindi S, Wolski K, Moon KW, Sipahi I, Schoenhagen P, Nissen SE. Effect of diabetes on progression of coronary atherosclerosis and arterial remodeling: a pooled analysis of 5 intravascular ultrasound trials. J Am Coll Cardiol. 2008;52:255-262.

3. Shi Y, Vanhoutte PM. Macro- and microvascular endothelial dysfunction in diabetes. J Diabetes. 2017;9:434-449.

4. Yuan T, Yang T, Chen H, Fu D, Hu Y, Wang J, Yuan Q, Yu H, Xu W, Xie X. New insights into oxidative stress and inflammation during diabetes mellitus-accelerated atherosclerosis. Redox Biol. 2019;20:247-260.

5. Kantharidis P, Wang B, Carew RM, Lan HY. Diabetes complications: the microRNA perspective. Diabetes. 2011;60:1832-1837.

6. Feng B, Chen S, McArthur K, Wu Y, Sen S, Ding Q, Feldman RD, Chakrabarti S. miR-146a-mediated extracellular matrix protein production in chronic diabetes complications. Diabetes. 2011;60:29752984.

7. Bhatt K, Lanting LL, Jia Y, Yadav S, Reddy MA, Magilnick N, Boldin M, Natarajan R. Anti-inflammatory role of microRNA-146a in the pathogenesis of diabetic nephropathy. J Am Soc Nephrol. 2016;27:2277-2288.

8. Feng Y, Chen L, Luo Q, Wu M, Chen Y, Shi X. Involvement of microRNA-146a in diabetic peripheral neuropathy through the regulation of inflammation. Drug Des Devel Ther. 2018;12:171-177.

9. Lu J, Wu DM, Zheng YL, Hu B, Cheng W, Zhang ZF, Li MQ. Troxerutin counteracts domoic acid-induced memory deficits in mice by inhibiting CCAAT/enhancer binding protein $\beta$-mediated inflammatory response and oxidative stress. J Immunol. 2013;190:34663479.

10. Geetha R, Radika MK, Priyadarshini E, Bhavani K, Anuradha CV. Troxerutin reverses fibrotic changes in the myocardium of high-fat high-fructose diet-fed mice. Mol Cell Biochem. 2015;407:263-279.

11. Zhang S, Li H, Zhang L, Li J, Wang R, Wang M. Effects of troxerutin on cognitive deficits and glutamate cysteine ligase subunits in the hippocampus of streptozotocin-induced type 1 diabetes mellitus rats. Brain Res. 2017;1657:355-360.

12. Shu L, Zhang W, Huang G, Huang C, Zhu X, Su G, Xu J. Troxerutin attenuates myocardial cell apoptosis following myocardial ischemiareperfusion injury through inhibition of miR-146a-5p expression. $J$ Cell Physiol. 2019;234:9274-9282.

13. Zabihi NA, Mousavi SM, Mahmoudabady M, Soukhtanloo M, 
Sohrabi F, Niazmand S. Teucrium polium L. improves blood glucose and lipids and ameliorates oxidative stress in heart and aorta of diabetic rats. Int J Prev Med. 2018;9:110.

14. Najafi M, Farajnia S, Mohammadi M, Badalzadeh R, Ahmadi Asl N, Baradaran B, Amani M. Inhibition of mitochondrial permeability transition pore restores the cardioprotection by postconditioning in diabetic hearts. J Diabetes Metab Disord. 2014;13:106.

15. Sampath S, Karundevi B. Effect of troxerutin on insulin signaling molecules in the gastrocnemius muscle of high fat and sucrose-induced type-2 diabetic adult male rat. Mol Cell Biochem. 2014;395:1127.

16. Schalkwijk CG, Stehouwer CD. Vascular complications in diabetes mellitus: the role of endothelial dysfunction. Clin Sci (Lond). 2005;109:143-159.

17. Lam TY, Seto SW, Lau YM, Au LS, Kwan YW, Ngai SM, Tsui KW. Impairment of the vascular relaxation and differential expression of caveolin- 1 of the aorta of diabetic $+\mathrm{db} /+\mathrm{db}$ mice. Eur J Pharmacol. 2006;546:134-141.

18. Mohammad A, Ali N, Reza B, Ali K. Effect of ascorbic acid supplementation on nitric oxide metabolites and systolic blood pressure in rats exposed to lead. Indian J Pharmacol. 2010;42:78-81.

19. Das Evcimen N, King GL. The role of protein kinase C activation and the vascular complications of diabetes. Pharmacol Res. 2007;55:498-510.

20. Bullon P, Newman HN, Battino M. Obesity, diabetes mellitus, atherosclerosis and chronic periodontitis: a shared pathology via oxidative stress and mitochondrial dysfunction? Periodontol 2000. 2014;64:139-153.

21. Kim F, Pham M, Maloney E, Rizzo NO, Morton GJ, Wisse BE, Kirk EA, Chait A, Schwartz MW. Vascular inflammation, insulin resistance, and reduced nitric oxide production precede the onset of peripheral insulin resistance. Arterioscler Thromb Vasc Biol. 2008;28:1982-1988.

22. Basta G, Schmidt AM, De Caterina R. Advanced glycation end products and vascular inflammation: implications for accelerated atherosclerosis in diabetes. Cardiovasc Res. 2004;63:582-592.
23. Dasu MR, Devaraj S, Zhao L, Hwang DH, Jialal I. High glucose induces toll-like receptor expression in human monocytes: mechanism of activation. Diabetes. 2008;57:3090-3098.

24. Patel S, Santani D. Role of NF-kappa B in the pathogenesis of diabetes and its associated complications. Pharmacol Rep. 2009;61:595603.

25. Yu Y, Zheng G. Troxerutin protects against diabetic cardiomyopathy through NF- $\mathrm{B} / \mathrm{AKT} / \mathrm{IRS} 1$ in a rat model of type 2 diabetes. Mol Med Rep. 2017;15:3473-3478.

26. Zhang H, Liu J, Qu D, Wang L, Luo JY, Lau CW, Liu P, Gao Z, Tipoe GL, Lee HK, Ng CF, Ma RC, Yao X, Huang Y. Inhibition of miR$200 \mathrm{c}$ restores endothelial function in diabetic mice through suppression of COX-2. Diabetes. 2016;65:1196-1207.

27. Yang M, Ye L, Wang B, Gao J, Liu R, Hong J, Wang W, Gu W, Ning G. Decreased miR-146 expression in peripheral blood mononuclear cells is correlated with ongoing islet autoimmunity in type 1 diabetes patients. J Diabetes. 2015;7:158-165.

28. García-Díaz DF, Pizarro C, Camacho-Guillén P, Codner E, Soto N, Pérez-Bravo F. Expression of miR-155, miR-146a, and miR-326 in T1D patients from Chile: relationship with autoimmunity and inflammatory markers. Arch Endocrinol Metab. 2018;62:34-40.

29. Feng B, Chen S, Gordon AD, Chakrabarti S. miR-146a mediates inflammatory changes and fibrosis in the heart in diabetes. J Mol Cell Cardiol. 2017;105:70-76.

30. Mann M, Mehta A, Zhao JL, Lee K, Marinov GK, Garcia-Flores Y, Lu LF, Rudensky AY, Baltimore D. An NF- $\mathrm{B}$-microRNA regulatory network tunes macrophage inflammatory responses. Nat Commun. 2017;8:851.

31. Ye EA, Steinle JJ. miR-146a attenuates inflammatory pathways mediated by TLR4/NF- $\kappa \mathrm{B}$ and TNF $\alpha$ to protect primary human retinal microvascular endothelial cells grown in high glucose. Mediators Inflamm. 2016;2016:3958453.

32. Huang Y, Liu Y, Li L, Su B, Yang L, Fan W, Yin Q, Chen L, Cui T, Zhang J, Lu Y, Cheng J, Fu P, Liu F. Involvement of inflammationrelated miR-155 and miR-146a in diabetic nephropathy: implications for glomerular endothelial injury. BMC Nephrol. 2014;15:142. 